\title{
Phase I Study of Rivoceranib, a Selective VEGFR-2 Angiogenesis Inhibitor, Administered Daily in Patients With Advanced Solid Tumors
}

\author{
Yoon-Koo Kang ( $\nabla$ ykkang@amc.seoul.kr) \\ Asan Medical Center, University of Ulsan College of Medicine \\ Min-Hee Ryu \\ Asan Medical Center \\ Yong Sang Hong \\ Asan Medical Center \\ Chang-Min Choi \\ Asan Medical Center \\ Tae Won Kim \\ Asan Medical Center \\ Baek-Yeol Ryoo \\ Asan Medical Center \\ Jeong Eun Kim \\ Asan Medical Center
}

Sang-We Kim

Asan Medical Center

John R. Weis

Huntsman Cancer Institute Cancer Hospital: University of Utah Health Huntsman Cancer Institute

Glynn Weldon Gilcrease

Huntsman Cancer Institute Cancer Hospital: University of Utah Health Huntsman Cancer Institute

Rachel Kingsford

Huntsman Cancer Institute Cancer Hospital: University of Utah Health Huntsman Cancer Institute

Nicole Orgain

Huntsman Cancer Institute Cancer Hospital: University of Utah Health Huntsman Cancer Institute

Se Ra Kim

Bukwang Pharamaceuticals Co. Ltd.

Cheol Hee Park

Elevar Therapeutics Inc

Madhav Sachar

Elevar Therapaeutics, Inc.

Arlo McGinn

Elevar Therapeutics Inc

Theresa L Werner

Huntsman Cancer Institute Cancer Hospital: University of Utah Health Huntsman Cancer Institute

Sunil Sharam

Huntsman Cancer Institute Cancer Hospital: University of Utah Health Huntsman Cancer Institute

\section{Research Article}

Keywords: Rivoceranib, apatinib, anti-angiogenesis, solid tumors, MAD 
Posted Date: May 27th, 2021

DOI: https://doi.org/10.21203/rs.3.rs-522994/v1

License: (0) (1) This work is licensed under a Creative Commons Attribution 4.0 International License. Read Full License 


\section{Abstract}

Rivoceranib is a highly potent and selective inhibitor of VEGFR-2 and subsequent angiogenesis through this receptor signaling pathway. This phase I study was the first global study with rivoceranib outside of China in Korean and Caucasian patients and was designed to determine the safety profile (including maximum tolerated dose), pharmacokinetics, and efficacy in patients with advanced solid tumors. Thirty-one adult patients with advanced malignant solid tumors were enrolled to investigate 6 dose levels of rivoceranib. Twenty-five patients were initially enrolled to 5 dose levels of rivoceranib from 81 to $685 \mathrm{mg}$ and an additional 6 patients were later enrolled in a supplemental study to evaluate the $805 \mathrm{mg}$ dose level. Rivoceranib was very well tolerated. At the $805 \mathrm{mg}$ dose level, 2 dose-limiting toxicities were observed but the $685 \mathrm{mg}$ dose was well tolerated over multiple cycles of therapy. The maximum tolerated dose for rivoceranib was $685 \mathrm{mg}$ (equivalent to $850 \mathrm{mg}$ rivoceranib mesylate) and recommended for further study in patients with advanced solid tumors. The most common adverse events were hypertension (all grades $\% / \geq G 3 \%: 58 / 29$ ), nausea (42/0), diarrhea (39/0), anorexia (32/3), and fatigue (29/6). Rivoceranib pharmacokinetics were proportional across all dose levels but interpatient variability was high. Of the 31 patients enrolled, 21 were evaluable for efficacy. In this evaluable group, partial response was recorded in 5 patients, stable disease in 10, and disease progression in 6 . Results indicate the potential clinical benefit of daily rivoceranib in patients with advanced malignant solid tumors with a tolerable safety profile.

Trial registration: NCT01497704 (ClinicalTrials.gov) registered on December 22, 2011 and NCT02711969 (ClinicalTrials.gov) registered on March 17, 2016.

\section{Introduction}

In contrast to conventional chemotherapy that targets proliferation of tumor cells, angiogenesis inhibitors primarily target neovascularization and/or survival of tumoral blood vessels [1, 2].

Proliferation of endothelial cells is targeted directly and inhibition of the release of proangiogenic growth factors by cancer or stromal cells is targeted indirectly. Vascular endothelial cell growth factor (VEGF) binds to VEGF receptors (VEGFR) inducing a series of vascular angiogenesis reactions such as cell proliferation, migration, blood vessel permeability and migration of stem cells from bone marrow [3-5].

The family members of VEGF receptors include: VEGFR-1 (FIt-1), VEGFR-2 (KDR/Flk-1), and VEGFR-3 (Flt-4). Vascular angiogenesis in tumors is mainly induced by VEGF binding to VEGFR-2 (KDR/Flk-I), which mediates microvascular permeability, endothelial cell proliferation, migration, invasion and survival [6-8] .

VEGFR-2 is regarded as the most sensitive marker for endothelial cell growth that directly controls tumor angiogenesis [9].

Autocrine/paracrine mechanisms in the processes of cancer cell survival and proliferation are mediated by the upregulation of VEGF/VEGFR-2 signaling [10-12].

VEGFR-2 signaling in tumor vascular endothelial cells is now recognized as a pivotal and rate-limiting step in tumor angiogenesis, and clinical studies have demonstrated that selective inhibition of VEGFR-2 can limit tumor growth and disease progression, resulting in improved overall survival [13].

Rivoceranib (also known as apatinib and YN968D1) is an orally administered, highly selective TKI of VEGFR-2 with demonstrated activity in treating various solid tumors, including gastric cancer [14]. Rivoceranib has been studied in China under the name apatinib in many clinical trials treating a number of solid tumors and was approved by the Chinese FDA for treatment of advanced gastric cancer in December of 2014. Rivoceranib is under further development globally as monotherapy for the treatment of gastric cancer [15].

Here we report the findings of the phase I dose escalation portion of a phase I/lla study evaluating for the first time the safety and efficacy of rivoceranib outside of China in Korean and Caucasian patients with advanced solid tumors.

\section{Methods}


The study population consisted of male or female patients of at least 18 years of age with any malignant solid tumors who were refractory or unable to tolerate conventional therapy. Major inclusion criteria included: measurable disease as defined by Response Evaluation Criteria in Solid Tumors (RECIST) version 1.1 as measured by a suitable radiographic technique; life expectancy of $\geq 3$ months; ability to swallow oral tablets; adequate bone marrow, renal, and liver function, and an Eastern Cooperative Oncology Group (ECOG) performance status of $\leq 2$.

\section{Study design}

This was a multi-site, open-label, safety, pharmacokinetics (PK), and preliminary efficacy study of rivoceranib. Patients were enrolled into the study at 2 sites: Asan Medical Center in Seoul, Korea, and Huntsman Cancer Institute in Salt Lake City, USA. The study used a standard $3+3$ dose-escalation scheme to establish the maximum tolerated dose (MTD) over a 28-day Dose-Limiting Toxicity (DLT) assessment period. The initial doses investigated in the study were $81 \mathrm{mg}, 201 \mathrm{mg}, 403 \mathrm{mg}, 604 \mathrm{mg}$, and $685 \mathrm{mg}$ PO QD (corresponding to $100 \mathrm{mg}, 250 \mathrm{mg}, 500 \mathrm{mg}, 750 \mathrm{mg}$, and $850 \mathrm{mg}$ rivoceranib mesylate) (NCT01497704). An additional dose level was added in a separate supplemental study at Asan Medical Center to investigate the $805 \mathrm{mg}$ PO QD dose level $(1,000 \mathrm{mg}$ rivoceranib mesylate) because the MTD was not reached in the initial 81-685 mg PO QD dose range (NCT02711969). Patients received rivoceranib daily in continuous 28-day cycles until disease progression, intolerable side effects, or withdrawal of consent. Rivoceranib was supplied in blister packs containing 10-tablets of either $81 \mathrm{mg}$ or $201 \mathrm{mg}$ of rivoceranib (as $100 \mathrm{mg}$ or $250 \mathrm{mg}$ rivoceranib mesylate respectively) and was administered once a day.

The primary objective was to investigate the safety and tolerability of a 28-day cycle of daily rivoceranib oral therapy while the secondary objectives were: to evaluate the PK profile of rivoceranib after a single dose and at steady-state; to obtain information regarding the pharmacodynamics of rivoceranib in humans; and to obtain additional information regarding the efficacy of rivoceranib in humans.

\section{Study evaluations}

All patients who received at least one dose of rivoceranib were considered evaluable for safety. Adverse events (AEs) were graded according to NCI-CTCAE v4.03 and were recorded at each visit along with concomitant medications.

An AE was considered a DLT if it occurred during the first 28-days of therapy and met one of the following criteria: at least possibly related to rivoceranib; grade 4 event; grade 3 febrile neutropenia; grade 3 hematologic toxicity with duration $>7$ days; grade 3 nonhematologic toxicity including grade 3 nausea, vomiting, and diarrhea that continued despite optimal medical management. If a DLT occurred in any dose, the cohort was expanded to 6 patients. If 2 DLTs were experienced the dose level was deemed intolerable. Prior to escalation to the next dose level, the medical monitor prepared a safety report that was reviewed and approved by all investigators and study personnel.

Patients were evaluated using RECIST v1.1 using an appropriate imaging technique such as CT scan or MRI at baseline (Day - 22 to - 1) and approximately every 8 weeks thereafter (every two 28-day cycles of treatment). The same imaging modality used at baseline was used consistently throughout all evaluations throughout the study to monitor a given patient. The ECOG performance assessment was performed at baseline (Day - 14 to - 1), at the end of the first 28-day cycle, and every two 28-day cycles after.

\section{Pharmacokinetics and pharmacodynamics}

Blood samples for determination of plasma PK profiles of rivoceranib that followed single (Day 1 ) and multiple dosing (after 28-days continuous dosing) were collected during the study. Blood was collected prior to dosing; at 30 and 60 minutes, and at 2, 4, 6, 8, 10, 24 , and 48 hours (single dose only) after dosing. Rivoceranib was isolated from plasma using liquid-liquid extraction and concentrations were determined using a validated HPLC-MS/MS method. The following pharmacokinetic parameters were calculated by non-compartmental modeling methods: the maximum observed concentration $\left(\mathrm{C}_{\max }\right)$, time corresponding to occurrence of $\mathrm{C}_{\max }$ $\left(t_{\text {max }}\right)$, total clearance $(C L / F)$, volume of distribution $\left(V_{z} / F\right)$, elimination rate constant $\left(\lambda_{z}\right)$, half-life $\left(t_{1 / 2}\right)$, and area under the concentration time curve $\left(\mathrm{AUC}_{(0-\mathrm{t})}\right.$ and $\left.\mathrm{AUC}_{(0-\infty)}\right)$ and the percentage of the $\mathrm{AUC}_{(0-\infty)}$ extrapolated to infinity (AUC\%).

Blood samples for pharmacodynamics were drawn at baseline and before dosing at the beginning of each two subsequent 28-day cycles of therapy. Pharmacodynamic markers included VEGF, soluble VEGFR-1 (sVEGR-1; Flt-1), sVEGFR-2 (KDR), sVEGFR-3, sTie-2, PIGF, and sVCAM-1. Pharmacodynamic markers were analyzed for significance using a paired t-test. 


\section{Results}

\section{Patients and drug exposure}

A total of 31 patients were enrolled ( 25 patients in the initial phase I study and 6 patients in the supplemental 805 mg dose level expansion study). Of these, 13 were discontinued, with 8 patients discontinuing due to adverse events (AEs). The mean dose taken was $500 \mathrm{mg}$ with an average duration of therapy of 5 months.

Patient baseline characteristics are presented in Table 1. Patient median age was 63 and most patients were male (68\%) and Caucasian (58\%). The majority of patients had gastric cancer (GC) (42\%) with other tumor types including colorectal (13\%), sarcoma $(10 \%)$, and a broad range of other tumor types. This patient population was heavily pretreated with $52 \%$ of all patients having received at least 3 prior lines of therapy and $29 \%$ of patients having received at least 4 prior lines. Most patients had received prior platinum and fluoropyrimidines (68\% and $61 \%$ respectively) and $36 \%$ had received some form of a prior anti-angiogenic agent. 
Table 1

Patient Baseline Characteristics

\begin{tabular}{|c|c|}
\hline Characteristics & Patients $(\mathrm{N}=31)$ \\
\hline \multicolumn{2}{|l|}{ Gender, n (\%) } \\
\hline Male & $21(68)$ \\
\hline Female & $10(32)$ \\
\hline Median age (range), years & $63(33-76)$ \\
\hline \multicolumn{2}{|l|}{ Race, n (\%) } \\
\hline White & $18(58)$ \\
\hline Asian & $13(42)$ \\
\hline ECOG PS 0/1/2, n & $6 / 23 / 2$ \\
\hline \multicolumn{2}{|c|}{ Prior chemotherapy regimens, $\mathrm{n}(\%)$} \\
\hline$\geq 1$ & $29(94)$ \\
\hline$\geq 2$ & $27(87)$ \\
\hline$\geq 3$ & $16(52)$ \\
\hline$\geq 4$ & $9(29)$ \\
\hline Unknown & $2(7)$ \\
\hline \multicolumn{2}{|c|}{ Prior anti-cancer therapies, n (\%) } \\
\hline Platinum & $21(68)$ \\
\hline Fluoropyrimidine & $19(61)$ \\
\hline Taxane & $15(48)$ \\
\hline Irinotecan & $13(42)$ \\
\hline Anti-angiogenic & $11(36)$ \\
\hline \multicolumn{2}{|l|}{ Tumor type, n (\%) } \\
\hline Gastric carcinoma & $13(42)$ \\
\hline Colorectal carcinoma & $4(13)$ \\
\hline Sarcoma & $3(10)$ \\
\hline Pancreatic carcinoma & $2(7)$ \\
\hline Renal cell carcinoma & $2(7)$ \\
\hline Neuroendocrine tumor & $2(7)$ \\
\hline Other & $5(16)$ \\
\hline
\end{tabular}

\section{DLTs and dose escalation}

DLTs for rivoceranib were identified in 3 patients and included malignant hypertension, febrile neutropenia, and anorexia (see Table 2). The MTD was determined to be $685 \mathrm{mg}$ rivoceranib ( $850 \mathrm{mg}$ rivoceranib mesylate). The original study escalated from 81 $\mathrm{mg}$ through to $685 \mathrm{mg}$ without identifying an intolerable dose. A second expansion cohort was later enrolled to investigate the 805 $\mathrm{mg}$ dose level (1,000 $\mathrm{mg}$ rivoceranib mesylate) and this dose was determined to be intolerable, thereby determining the $685 \mathrm{mg}$ dose level as the MTD. 
Table 2

Dose escalation and dose-limiting toxicities

\begin{tabular}{|lll|}
\hline Dose level & N & Dose-limiting toxicities \\
\hline $81 \mathrm{mg}$ & 5 & \\
$201 \mathrm{mg}$ & 9 & Grade 4 malignant hypertension $(\mathrm{n}=1)$ \\
$403 \mathrm{mg}$ & 4 & \\
$604 \mathrm{mg}$ & 4 & \\
$685 \mathrm{mg}$ & 3 & \\
$805 \mathrm{mg}$ & 6 & Grade 3 febrile neutropenia $(n=1)$ \\
& & Grade 3 anorexia and fatigue $(n=1)$ \\
\hline
\end{tabular}

In the original dose escalation, a single DLT of malignant hypertension was identified at the $201 \mathrm{mg}$ dose level. This renal cell carcinoma patient had a prior history of moderate hypertension, a prior left nephrectomy, and abnormally high plasma concentrations of rivoceranib for the dose level $\left(A_{U C} C_{0-24}: 5,583 \mathrm{hr} \cdot \mathrm{ng} / \mathrm{mL} ; C_{\max }: 440 \mathrm{ng} / \mathrm{mL}\right)$. Rivoceranib was discontinued and the hypertension resolved.

A DLT of grade 3 febrile neutropenia occurred in one of the first 3 patients at the $805 \mathrm{mg}$ dose level. The febrile neutropenia resolved subsequent to administration of GCSF and antibiotics. A DLT of grade 3 anorexia and fatigue occurred in an additional patient at the $805 \mathrm{mg}$ dose level which resulted in the declaration of the $685 \mathrm{mg}$ dose level as the MTD.

\section{Adverse Events}

A summary of the toxicity profile of rivoceranib across all investigated dose levels is displayed in Table 3 . All patients who received at least one dose of rivoceranib were included in the safety analysis. All patients experienced at least one AE over the duration of the study with $61 \%$ of patients experiencing a serious AE (SAE). There were no deaths associated with rivoceranib administration and AEs leading to discontinuation of rivoceranib were seen in only $29 \%$ of patients. 
Table 3

Adverse events occurring in $\geq 10 \%$ of patients

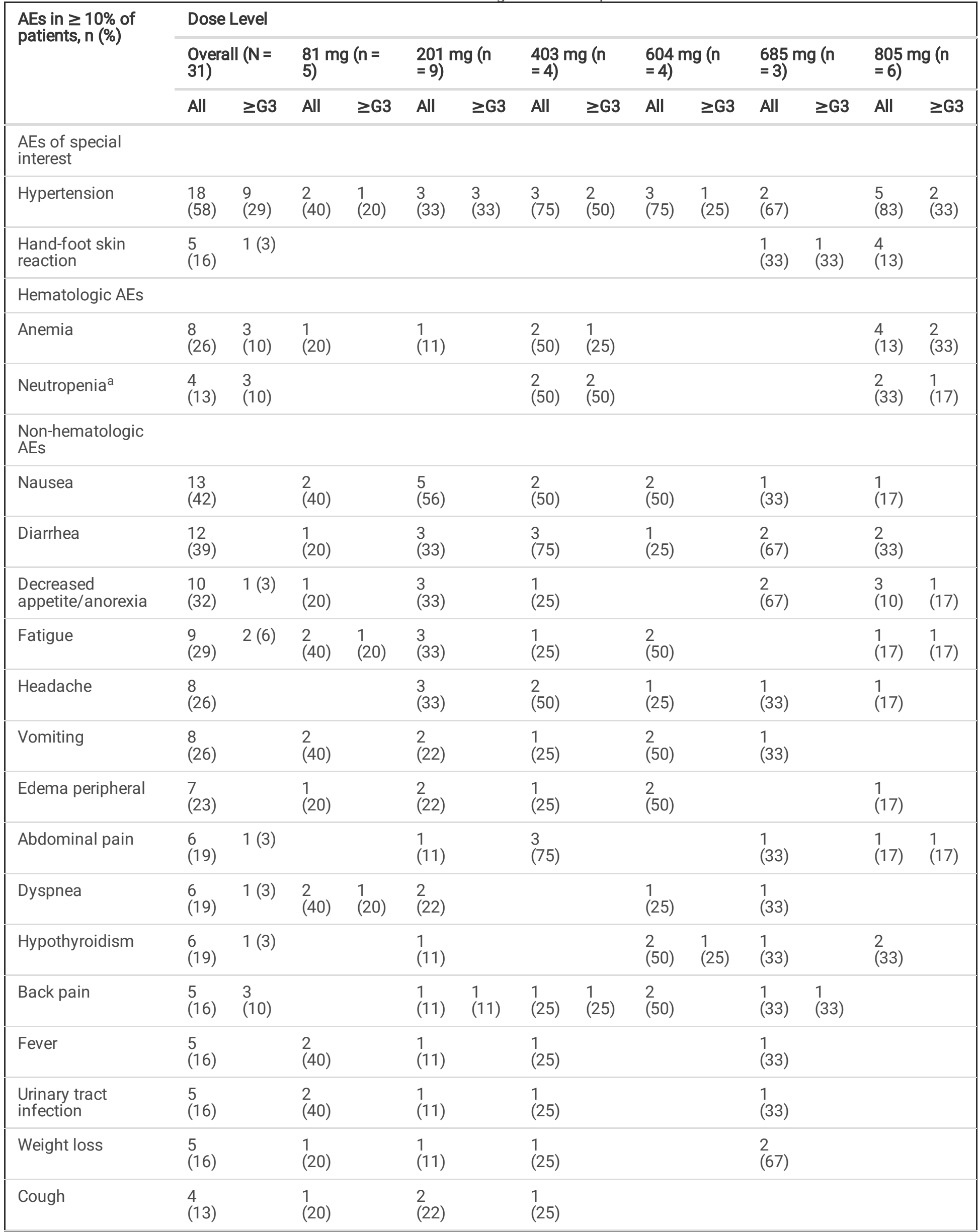

Page $8 / 15$ 


\begin{tabular}{|c|c|c|c|c|c|c|c|c|c|c|c|c|c|c|}
\hline \multirow{3}{*}{$\begin{array}{l}\text { AEs in } \geq 10 \% \text { of } \\
\text { patients, } n(\%)\end{array}$} & \multicolumn{14}{|c|}{ Dose Level } \\
\hline & \multicolumn{2}{|c|}{$\begin{array}{l}\text { Overall }(\mathrm{N}= \\
31)\end{array}$} & \multicolumn{2}{|c|}{$\begin{array}{l}81 \mathrm{mg}(\mathrm{n}= \\
5)\end{array}$} & \multicolumn{2}{|c|}{$\begin{array}{l}201 \mathrm{mg}(\mathrm{n} \\
=9)\end{array}$} & \multicolumn{2}{|c|}{$\begin{array}{l}403 \mathrm{mg}(\mathrm{n} \\
=4)\end{array}$} & \multicolumn{2}{|c|}{$\begin{array}{l}604 \mathrm{mg}(\mathrm{n} \\
=4)\end{array}$} & \multicolumn{2}{|c|}{$\begin{array}{l}685 \mathrm{mg}(\mathrm{n} \\
=3)\end{array}$} & \multicolumn{2}{|c|}{$\begin{array}{l}805 \mathrm{mg}(\mathrm{n} \\
=6)\end{array}$} \\
\hline & All & $\geq \mathbf{G} 3$ & All & $\geq \mathbf{G} 3$ & All & $\geq \mathbf{G} 3$ & All & $\geq \mathbf{G} 3$ & All & $\geq \mathbf{G} 3$ & All & $\geq \mathbf{G} 3$ & All & $\geq \mathbf{G} 3$ \\
\hline Dehydration & $\begin{array}{l}4 \\
(13)\end{array}$ & & $\begin{array}{l}2 \\
(40)\end{array}$ & & & & $\begin{array}{l}1 \\
(25)\end{array}$ & & & & $\begin{array}{l}1 \\
(33)\end{array}$ & & & \\
\hline Dizziness & $\begin{array}{l}4 \\
(13)\end{array}$ & & $\begin{array}{l}1 \\
(20)\end{array}$ & & & & $\begin{array}{l}2 \\
(50)\end{array}$ & & $\begin{array}{l}1 \\
(25)\end{array}$ & & & & & \\
\hline Dysphonia & $\begin{array}{l}4 \\
(13)\end{array}$ & & & & & & & & & & & & $\begin{array}{l}4 \\
(13)\end{array}$ & \\
\hline Pleural effusion & $\begin{array}{l}4 \\
(13)\end{array}$ & & $\begin{array}{l}2 \\
(40)\end{array}$ & & $\begin{array}{l}1 \\
(11)\end{array}$ & & & & $\begin{array}{l}1 \\
(25)\end{array}$ & & & & & \\
\hline Stomatitis & $\begin{array}{l}4 \\
(13)\end{array}$ & $1(3)$ & & & & & & & & & $\begin{array}{l}1 \\
(33)\end{array}$ & & $\begin{array}{l}3 \\
(10)\end{array}$ & $\begin{array}{l}1 \\
(17)\end{array}$ \\
\hline \multicolumn{15}{|l|}{ Lab abnormalities } \\
\hline Hyperkalemia & $\begin{array}{l}5 \\
(16)\end{array}$ & & & & $\begin{array}{l}3 \\
(33)\end{array}$ & & & & & & $\begin{array}{l}1 \\
(33)\end{array}$ & & $\begin{array}{l}1 \\
(17)\end{array}$ & \\
\hline Hypophosphatemia & $\begin{array}{l}5 \\
(16)\end{array}$ & $\begin{array}{l}5 \\
(16)\end{array}$ & & & $\begin{array}{l}1 \\
(11)\end{array}$ & $\begin{array}{l}1 \\
(11)\end{array}$ & & & $\begin{array}{l}1 \\
(25)\end{array}$ & $\begin{array}{l}1 \\
(25)\end{array}$ & $\begin{array}{l}1 \\
\text { (33) }\end{array}$ & $\begin{array}{l}1 \\
(33)\end{array}$ & $\begin{array}{l}2 \\
(33)\end{array}$ & $\begin{array}{l}2 \\
(33)\end{array}$ \\
\hline Hypokalemia & $\begin{array}{l}4 \\
(13)\end{array}$ & $1(3)$ & $\begin{array}{l}1 \\
(20)\end{array}$ & & $\begin{array}{l}1 \\
(11)\end{array}$ & & & & $\begin{array}{l}1 \\
(25)\end{array}$ & & & & $\begin{array}{l}1 \\
(17)\end{array}$ & $\begin{array}{l}1 \\
(17)\end{array}$ \\
\hline
\end{tabular}

Most AEs were of low severity (grade 1 and 2). The most common AEs were hypertension (58\%), nausea (42\%), diarrhea (39\%), and anorexia/decreased appetite (32\%). Some AEs were more prevalent at higher doses with hand-foot skin reaction only observed at dose levels $\geq 685 \mathrm{mg} /$ day and anemia occurring in 4 of 6 patients at the $805 \mathrm{mg} /$ day dose level. While hypertension was only observed in $36 \%$ of patients receiving $201 \mathrm{mg} /$ day of rivoceranib or less, $76 \%$ of patients receiving $403 \mathrm{mg} /$ day or higher experienced hypertension of any grade.

\section{Pharmacokinetics}

Derived pharmacokinetic parameters from the blood plasma concentrations of rivoceranib on study day 1 (single dose) and after 28 days of continuous oral dosing (steady-state) are presented in Table 4. After a single oral administration of rivoceranib, absorption was relatively fast, with median $T_{\max }$ increasing from 1.98 hours ( $81 \mathrm{mg}$ dose) to 5.90 hours ( $805 \mathrm{mg}$ dose). After steady-state was achieved, median $\mathrm{T}_{\max }$ was more consistent $(1.25-4.00 \mathrm{~h}$ ) and did not display a clear dose-related trend (Table 4). With a single oral dose, $\mathrm{C}_{\mathrm{max}}$ also increased proportionally with a geometric mean of $63 \mathrm{ng} / \mathrm{ml}$ ( $81 \mathrm{mg}$ dose) to $587 \mathrm{ng} / \mathrm{ml}$ (805 mg dose). Similar to $\mathrm{C}_{\text {max }}$, the geometric means for $\mathrm{AUC}_{0-24}$ and $\mathrm{AUC}_{0-\infty}$ also increased with dose from 403 and $374 \mathrm{~h} \bullet \mathrm{ng} / \mathrm{ml}(81 \mathrm{mg}$ dose) to 7,349 and $11,196 \mathrm{~h} \cdot \mathrm{ng} / \mathrm{ml}$ (805 $\mathrm{mg}$ dose). Variability in $\mathrm{C}_{\max }, \mathrm{AUC}_{0-24}$ and $\mathrm{AUC}_{0-\infty}$ measured by geometric \%CV was $27-130 \%, 10-122 \%$ and 6-145\%, respectively. 
Table 4

Plasma pharmacokinetics of oral rivoceranib at single dose and steady-state

\begin{tabular}{|c|c|c|c|c|c|c|c|c|}
\hline Day & PK Parameter & Statistic & $\begin{array}{l}81 \mathrm{mg} \\
\mathrm{n}=5\end{array}$ & $\begin{array}{l}201 \mathrm{mg} \\
\mathrm{n}=9\end{array}$ & $\begin{array}{l}403 \mathrm{mg} \\
\mathrm{n}=4\end{array}$ & $\begin{array}{l}604 \mathrm{mg} \\
\mathrm{n}=4\end{array}$ & $\begin{array}{l}685 \mathrm{mg} \\
\mathrm{n}=3\end{array}$ & $\begin{array}{l}805 \mathrm{mg} \\
\mathrm{n}=3\end{array}$ \\
\hline \multirow[t]{6}{*}{$\begin{array}{l}\text { Single } \\
\text { Dose }\end{array}$} & $\mathrm{C}_{\max }(\mathrm{ng} / \mathrm{mL})$ & $\begin{array}{l}\text { Geometric } \\
\text { mean }\end{array}$ & $63(60)$ & $96(97)$ & $347(96)$ & $445(29)$ & $426(100)$ & $587(25)$ \\
\hline & $\mathrm{T}_{\max }(\mathrm{h})$ & Median & 1.98 & 2.17 & 2.79 & 3.78 & 4.03 & 5.90 \\
\hline & $t_{1 / 2}(h)$ & $\begin{array}{l}\text { Geometric } \\
\text { mean }\end{array}$ & $\begin{array}{l}7.8 \\
(65.0)\end{array}$ & $\begin{array}{l}12.5 \\
(38.7)^{\mathrm{a}}\end{array}$ & $\begin{array}{l}13.4 \\
(14.2)^{\mathrm{a}}\end{array}$ & $\begin{array}{l}12.4 \\
(59.0)\end{array}$ & $\begin{array}{l}11.4 \\
(40.2)\end{array}$ & $\begin{array}{l}12.9 \\
(21.1)\end{array}$ \\
\hline & $\begin{array}{l}\mathrm{AUC}_{0-24} \\
\text { (h.ng/mL) }\end{array}$ & $\begin{array}{l}\text { Geometric } \\
\text { mean }\end{array}$ & $400(69)$ & $\begin{array}{l}1008 \\
(107)\end{array}$ & 3007 (49) & 4047 (38) & $4715(63)$ & $7483(10)$ \\
\hline & $\begin{array}{l}\mathrm{AUC}_{0-\infty} \\
(\mathrm{h} \cdot \mathrm{ng} / \mathrm{mL})\end{array}$ & $\begin{array}{l}\text { Geometric } \\
\text { mean }\end{array}$ & $\begin{array}{l}373.8 \\
(74)\end{array}$ & $\begin{array}{l}1349 \\
(105)^{\mathrm{a}}\end{array}$ & $\begin{array}{l}5308 \\
(26)^{\mathrm{a}}\end{array}$ & $5834(53)$ & $6378(64)$ & $11339(6)$ \\
\hline & & & $\mathrm{n}=3$ & $n=6$ & $n=3$ & $n=3$ & $\mathrm{n}=3$ & $\mathrm{n}=2$ \\
\hline \multirow[t]{4}{*}{$\begin{array}{l}\text { Steady- } \\
\text { state }\end{array}$} & $\mathrm{C}_{\max }(\mathrm{ng} / \mathrm{mL})$ & $\begin{array}{l}\text { Geometric } \\
\text { mean }\end{array}$ & $\begin{array}{l}71.6 \\
(41.5)\end{array}$ & $\begin{array}{l}235.4 \\
(43.9)\end{array}$ & $\begin{array}{l}508.8 \\
(73.6)\end{array}$ & $\begin{array}{l}943.0 \\
(55.6)\end{array}$ & $\begin{array}{l}582.3 \\
(50.0)\end{array}$ & $\begin{array}{l}503.0 \\
(85.5)\end{array}$ \\
\hline & $\mathrm{T}_{\max }(\mathrm{h})$ & Median & 2.05 & 4.00 & 4.00 & 2.00 & 2.00 & 1.25 \\
\hline & $t_{1 / 2}(h)$ & $\begin{array}{l}\text { Geometric } \\
\text { mean }\end{array}$ & $\mathrm{N} / \mathrm{C}$ & $\begin{array}{l}10.6 \\
(19.4)^{a}\end{array}$ & $\begin{array}{l}13.3 \\
(14.2)\end{array}$ & $\begin{array}{l}8.6 \\
(20.7)^{a}\end{array}$ & $\begin{array}{l}15.5 \\
(125.4)\end{array}$ & $\begin{array}{l}11.5 \\
(16.0)\end{array}$ \\
\hline & $\mathrm{AUC}_{\mathbb{\bigotimes}}(\mathrm{h} \cdot \mathrm{ng} / \mathrm{mL})$ & $\begin{array}{l}\text { Geometric } \\
\text { mean }\end{array}$ & $599(28)$ & $2567(42)$ & $5207(28)$ & $6833(78)$ & $7386(63)$ & $8197(81)$ \\
\hline \multicolumn{9}{|c|}{$\begin{array}{l}\text { Data are presented as mean (standard deviation) or geometric mean (\%CV). Abbreviations: } \mathrm{C}_{\text {max }} \text { : maximum observed plasma } \\
\text { concentration; } \mathrm{T}_{\text {max }} \text { : time at which maximum plasma concentration is observed; } \mathrm{t}_{1 / 2} \text { : terminal phase plasma half-life; } \mathrm{AUC}_{0}-24 \text { : } \\
\text { area under the plasma concentration-time curve from } 0 \text { to } 24 \text { hours; } \mathrm{AUC}_{\mathbb{V}} \text { : area under the plasma concentration-time curve to the } \\
\text { end of the dosing period; } \mathrm{N} / \mathrm{C} \text { : not calculated. }{ }^{\mathrm{a}} \mathrm{n}-1 \text { subjects available for analysis. }\end{array}$} \\
\hline
\end{tabular}

After multiple oral doses, the geometric mean $\mathrm{C}_{\text {max }}$ increased from $72 \mathrm{ng} / \mathrm{ml}$ ( $81 \mathrm{mg}$ dose) to $943 \mathrm{ng} / \mathrm{ml}$ (403 mg dose) then decreased to $503 \mathrm{ng} / \mathrm{ml}$ at the $805 \mathrm{mg}$ dose. Geometric \%CV for $\mathrm{C}_{\max }$ at steady-state ranged from $50-130 \%$. AUC $\mathrm{C}_{\mathbb{\nabla}}$ increased with dose from $599 \mathrm{~h} \bullet \mathrm{ng} / \mathrm{ml}$ ( $81 \mathrm{mg}$ dose) to $8,002 \mathrm{~h} \bullet \mathrm{ng} / \mathrm{ml}$ (805 $\mathrm{mg}$ dose) with a \%CV range of $28-122 \%$. With single dose as well as steady-state, average half-life $\left(\mathrm{t}_{1 / 2}\right)$ was consistent 8.7-13.4 hours for all the doses except for steady-state dose of $685 \mathrm{mg}$ dose where $t_{1 / 2}$ was 27.2 hours.

Dose proportionality analysis revealed that the pharmacokinetics of rivoceranib were proportional between $81 \mathrm{mg}$ and $805 \mathrm{mg}$ following single and multiple dose administration for $\mathrm{C}_{\max }$ and $\mathrm{AUC}_{0-24}, \mathrm{AUC}_{0-\infty}$, and $\mathrm{AUC}_{\mathbb{\bigotimes}}(\mathrm{Table} 5)$. 
Table 5

Dose proportionality calculations from $81 \mathrm{mg}$ to $805 \mathrm{mg}$ for single and multiple ascending doses

\begin{tabular}{|lllll|}
\hline PK Parameter & SAD/MAD & $\mathbf{N}$ & Intercept & Slope $(95 \% \mathrm{Cl})$ \\
\hline Cmax & SAD & 28 & -0.73 & $1.05(0.65-1.45)$ \\
\cline { 2 - 5 } & MAD & 27 & 0.11 & $0.99(0.63-1.35)$ \\
\hline AUC $_{0-24}$ & SAD & 28 & 0.46 & $1.24(0.88-1.59)$ \\
\hline AUC $_{\square}$ & MAD & 27 & 1.84 & $1.09(0.74-1.45)$ \\
\hline AUC $_{0-\infty}$ & SAD & 24 & -0.24 & $1.41(0.98-1.84)$ \\
\cline { 2 - 5 } & MAD & 24 & 4.06 & $0.77(0.41-1.12)$ \\
\hline aSAD: single ascending dose; MAD: multiple ascending dose \\
\hline
\end{tabular}

\section{Pharmacodynamics}

Plasma levels of soluble VEGFR-1 and VEGFR-2 decreased significantly over 2 cycles of continuous daily therapy (56 days). VEGFR-1 levels decreased $79.1 \%$ from $448.6 \mathrm{ng} / \mathrm{mL}$ to $93.9 \mathrm{ng} / \mathrm{mL}(\mathrm{n}=16)$ and VEGFR-2 levels decreased $21.2 \%$ from $37.2 \mathrm{ng} / \mathrm{mL}$ to 29.3 $\mathrm{ng} / \mathrm{mL}(\mathrm{n}=16)$. Changes in plasma levels of VEGFR-3, PIGF, Tie-2, sVCAM-1 and VEGF did not change significantly.

\section{Efficacy}

Efficacy across all dose levels is presented in Table 6. Overall, 21 out of the 31 enrolled patients had tumor assessments beyond baseline and were included in the efficacy analysis. Partial responses were observed in 5 patients ( $3 \mathrm{GC}, 1$ mesothelioma, and 1 renal cell carcinoma [RCC]), yielding an objective response rate (ORR) of $24 \%$ (95\% confidence interval [Cl]: 6-42\%). Stable disease was observed as a best response in an additional 10 patients, yielding a disease control rate of $71 \%$ (95\% Cl: $52-91 \%)$. Progressive disease as a best response was observed in 6 patients (29\%) and no patients achieved a complete response. Of the partial responses achieved during the study, 3 were highly durable with one response continuing 34.0 months (GC), a second continuing 12.0 months (RCC), and the last continuing 9.2 months (GC).

Table 6

Efficacy summary of best response by dose level

\begin{tabular}{|c|c|c|c|c|c|c|c|}
\hline Dose Level & Enrolled & Evaluable & PR & SD & PD & ORR & DCR \\
\hline $81 \mathrm{mg}$ & 5 & 3 & & & 3 & & \\
\hline $201 \mathrm{mg}$ & 9 & 5 & $2^{\mathrm{a}}$ & 3 & & $40 \%$ & $100 \%$ \\
\hline $403 \mathrm{mg}$ & 4 & 4 & 1 & 3 & & $25 \%$ & $100 \%$ \\
\hline $604 \mathrm{mg}$ & 4 & 3 & & 2 & 1 & & $67 \%$ \\
\hline $685 \mathrm{mg}$ & 3 & 3 & 1 & 1 & 1 & $33 \%$ & $67 \%$ \\
\hline $805 \mathrm{mg}$ & 6 & 3 & $1^{\mathrm{b}}$ & $1^{\mathrm{b}}$ & 1 & $33 \%$ & $67 \%$ \\
\hline All dose levels & 31 & 21 & 5 & 10 & 6 & $24 \%$ & $71 \%$ \\
\hline
\end{tabular}


The median progression-free survival (mPFS) for all patients was 5.1 months ( $95 \% \mathrm{Cl}: 2.0-13.1)$. In the gastric cancer subset of patients, the mPFS was 4.5 months (95\% Cl: 1.2-16.8) (Fig. 1).

\section{Discussion}

This study reported on the first experience with rivoceranib (also known as apatinib) outside of China in Korean and Caucasian patients. This study investigated 6 escalating oral daily doses of rivoceranib from $81 \mathrm{mg}$ to $805 \mathrm{mg}$ rivoceranib PO QD and determined that the maximum tolerated dose, and the dose recommended for further investigation is $685 \mathrm{mg}$ PO QD.

Rivoceranib was generally well tolerated in the study with $82.3 \%$ of all reported adverse events grade 1 and grade 2 . All patients experienced at least one treatment-emergent $A E$ with $74 \%$ of patients experiencing an $A E$ that was deemed related to administration of rivoceranib. Seventy-seven percent of patients experienced an AE $\geq$ grade 3 in severity, and $61 \%$ had serious adverse events. The reported adverse events were consistent with toxicities related to advanced cancer with the notable exception of hypertension and hand-foot syndrome which are related to the anti-angiogenic mechanism of action and common in other compounds in the same class [16].

The adverse event profile was highly similar to that seen in the dose escalation study performed in China; however, while rates of proteinuria were reported at approximately $30 \%$ in the Chinese study, this AE was largely unreported in this study. The tolerability of the drug is supported by the long durations of treatment in many of the subjects with 2 patients receiving the drug daily for approximately 3 years and 3 additional patients receiving rivoceranib for over 1 year.

Statistically, the determination of dose proportionality could not be excluded for both single dose and steady-state as the $95 \%$ confidence interval of the slope for all dose proportional parameters $\left(C_{\max }, A U C\right)$ contained 1 . Visually, however, it appeared that at steady-state $C_{\max }$ plateaued at $403 \mathrm{mg}$ while AUC leveled off at $403 \mathrm{mg}$ and higher. At single $201 \mathrm{mg}$ dose, $\mathrm{C}_{\max }$ and AUC were > 3fold lower than in previously published report (conducted after this study) evaluating ethnic difference on pharmacokinetics of rivoceranib [17]. The difference in the study could be explained by low subject size in current population, variation in exposure in healthy vs patient population or due to presence of large variblity in exposure due to low bioavailability.

While the search for circulating biomarkers which are predictive of response to anti-angiogenic therapy has been unsuccessful, the decrease in VEGFR-2 levels over time is indicative of on-target inhibition and is similar to the decrease observed in other studies in gastric cancer with inhibitors of VEGFR-2 [18].

This study presented significant evidence of the antitumor activity of rivoceranib with $24 \%$ of evaluable patients exhibiting partial responses ( $30 \%$ decrease or greater from baseline). An additional 10 patients had a best response of stable disease, yielding an overall disease control rate of $71 \%$. Of note, most of the partial responses were very durable with 3 patients maintaining the partial response for 9 months or longer and one patient maintaining for 34 months. Three of the partial responses occurred in patients receiving the $685 \mathrm{mg}$ daily dose; however, responses were also observed at both the $403 \mathrm{mg}$ and $201 \mathrm{mg}$ doses. This data compared well with the reported phase I study of rivoceranib in China where they reported a similar ORR and DCR (19\% and $84 \%$ respectively) [19].

Progression-free survival was also very promising in this highly pre-treated patient population with a mPFS of 5.1 months for all patients and 4.5 months for the advanced/metastatic gastric cancer patient population. As overall survival was not included as an objective in the study, collection of survival data was limited only to deaths that occurred while patients participated in the trial. Overall, death was only reported in 3 patients during the conduct of the study and no deaths were deemed related to rivoceranib.

Overall, this study reports the first experience with rivoceranib outside of China and demonstrated that the results observed in China were highly replicable with similar efficacy and safety profiles in Caucasian and Korean patients. Further investigation of rivoceranib in solid tumors is already underway outside of China with ongoing programs in gastrointestinal cancers including gastric and colorectal cancer and other solid tumors. [20-22]. A prospective, randomized, double-blinded, placebo-controlled, phase III study (the ANGEL study) to evaluate the efficacy and safety of rivoceranib plus best supportive care in patients with advanced or metastatic gastric cancer [15] (NCT03042611) has been completed and a phase III study in first-line hepatocellular carcinoma of rivoceranib in combination with the anti-PD-1 inhibitor camrelizumab (NCT03764293) is currently in progress. 


\section{Declarations}

\section{Acknowledgements}

We thank the patients and their families for their participation, and we thank the co-investigators and study teams for making this study possible. Writing and editorial assistance was provided by Miller Medical via funding from Elevar Therapeutics.

\section{Author Contributions}

SS was the principal investigator of the phase 1 study. TW became the PI near the conclusion of the trial. MHR, SRP, YSH, CHC, TWK, BYR, JEK, SWK, JRW, GWG, CD, RK, JC, NO, SRK, and CHP all participated in conducting the study. MS, and AM analyzed data and edited the manuscript. YKK was the PI for expansion cohort and edited the manuscript. All authors meet ICMJE criteria for authorship.

\section{Funding}

The study was sponsored by Elevar Therapeutics and Bukwang Pharm Co., Ltd.

\section{Conflicts of interest}

SS did not have any conflicts of interest when he was the PI of the trial. YKK is a consultant for ALX Oncology, Amgen, BMS, Blueprint, Daehwa, Macrogenics, Merck (MSD), Novartis, Surface Oncology, Zymeworks. M.S., C.H.P., and A.N.M. are employees of Elevar Therapeutics. SRK is an employee of Bukwang Pharm Co., Ltd.

\section{Availability of data and material}

Data will be made available for request after product approval in the US and EU or after product development is discontinued.

\section{Code availability}

Not applicable

\section{Ethics approval}

The studies were conducted in accordance with the principles set forth in the Declaration of Helsinki, including all amendments up to and including the 1996 revision, the Guidelines of the International Council on Harmonization (ICH) on Good Clinical Practice (GCP) (CPMP/ICH/135/95), privacy regulations, and other applicable regulatory requirements.

\section{Consent for publication}

For the content and final editorial decision of the publication the authors were fully responsible. All the authors were involved in the approved final version for submission.

\section{Consent to participate}

Prior to participation in any study procedure, each potential study participant provided signed acknowledgement of their freely given informed consent.

\section{References}

1. Ferrara N, Kerbel RS. Angiogenesis as a therapeutic target. Nature. 2005;438(7070):967-74. doi: 10.1038/nature04483.

2. Zirlik K, Duyster J. Anti-Angiogenics: Current Situation and Future Perspectives. Oncol Res Treat. 2018;41(4):166-71. doi: $10.1159 / 000488087$.

3. Hoeben A, Landuyt B, Highley MS, Wildiers H, Van Oosterom AT, De Bruijn EA. Vascular endothelial growth factor and angiogenesis. Pharmacol Rev. 2004;56(4):549-80. doi: 10.1124/pr.56.4.3. 
4. Yoo SY, Kwon SM. Angiogenesis and its therapeutic opportunities. Mediators Inflamm. 2013;2013:127170. doi: $10.1155 / 2013 / 127170$.

5. Connolly DT, Heuvelman DM, Nelson R, Olander JV, Eppley BL, Delfino JJ, et al. Tumor vascular permeability factor stimulates endothelial cell growth and angiogenesis. J Clin Invest. 1989;84(5):1470-8. doi: 10.1172/JCI114322.

6. Waltenberger J, Claesson-Welsh L, Siegbahn A, Shibuya M, Heldin CH. Different signal transduction properties of KDR and Flt1, two receptors for vascular endothelial growth factor. J Biol Chem. 1994;269(43):26988-95.

7. de Vries C, Escobedo JA, Ueno H, Houck K, Ferrara N, Williams LT. The fms-like tyrosine kinase, a receptor for vascular endothelial growth factor. Science. 1992;255(5047):989-91. doi: 10.1126/science.1312256.

8. Terman BI, Dougher-Vermazen M, Carrion ME, Dimitrov D, Armellino DC, Gospodarowicz D, et al. Identification of the KDR tyrosine kinase as a receptor for vascular endothelial cell growth factor. Biochemical and Biophysical Research Communications. 1992;187(3):1579-86. doi: https://doi.org/10.1016/0006-291X(92)90483-2.

9. Niu G, Chen X. Vascular endothelial growth factor as an anti-angiogenic target for cancer therapy. Curr Drug Targets. 2010;11(8):1000-17. doi: 10.2174/138945010791591395.

10. Chatterjee S, Heukamp LC, Siobal M, Schottle J, Wieczorek C, Peifer M, et al. Tumor VEGF:VEGFR2 autocrine feed-forward loop triggers angiogenesis in lung cancer. J Clin Invest. 2013;123(4):1732-40. doi: 10.1172/JCI65385.

11. Abhinand CS, Raju R, Soumya SJ, Arya PS, Sudhakaran PR. VEGF-A/VEGFR2 signaling network in endothelial cells relevant to angiogenesis. J Cell Commun Signal. 2016;10(4):347-54. doi: 10.1007/s12079-016-0352-8.

12. Goel HL, Mercurio AM. VEGF targets the tumour cell. Nat Rev Cancer. 2013;13(12):871-82. doi: 10.1038/nrc3627.

13. Hicklin DJ, Ellis LM. Role of the vascular endothelial growth factor pathway in tumor growth and angiogenesis. J Clin Oncol. 2005;23(5):1011-27. doi: 10.1200/JC0.2005.06.081.

14. Li J, Qin S, Xu J, Xiong J, Wu C, Bai Y, et al. Randomized, Double-Blind, Placebo-Controlled Phase III Trial of Apatinib in Patients With Chemotherapy-Refractory Advanced or Metastatic Adenocarcinoma of the Stomach or Gastroesophageal Junction. J Clin Oncol. 2016;34(13):1448-54. doi: 10.1200/JC0.2015.63.5995.

15. Kang Y-K, Boku N, Kang WK, Yoon HH, Cascinu S, Al-Batran S-E, et al. A prospective, randomized, double-blinded, placebocontrolled, phase III study to evaluate the efficacy and safety of apatinib plus best supportive care (BSC) compared to placebo plus BSC in patients with advanced or metastatic gastric cancer: The ANGEL study. Journal of Clinical Oncology. 2017;35(15_suppl):TPS4138-TPS. doi: 10.1200/JC0.2017.35.15_suppl.TPS4138.

16. Elice F, Rodeghiero F. Side effects of anti-angiogenic drugs. Thrombosis Research. 2012;129:S50-S3. doi: https://doi.org/10.1016/S0049-3848(12)70016-6.

17. Sachar M, Park CH, Pesco-Koplowitz L, Koplowitz B, McGinn A. Absence of ethnic difference on single-dose pharmacokinetics of rivoceranib between healthy male Caucasian, Japanese, and Chinese subjects. Fundam Clin Pharmacol. 2021;35(2):485-95. doi: $10.1111 /$ fcp. 12619 .

18. Shah MA, Wainberg ZA, Catenacci DV, Hochster HS, Ford J, Kunz P, et al. Phase II study evaluating 2 dosing schedules of oral foretinib (GSK1363089), cMET/VEGFR2 inhibitor, in patients with metastatic gastric cancer. PLoS One. 2013;8(3):e54014. doi: 10.1371/journal.pone.0054014.

19. Li J, Zhao X, Chen L, Guo H, Lv F, Jia K, et al. Safety and pharmacokinetics of novel selective vascular endothelial growth factor receptor-2 inhibitor YN968D1 in patients with advanced malignancies. BMC Cancer. 2010;10:529. doi: 10.1186/1471-2407-10529.

20. Zhang S, Liang F. Phase II study of apatinib: A novel VEGFR inhibitor in pretreated patients with metastatic penile cancer. Journal of Clinical Oncology. 2019;37(7_suppl):TPS538-TPS. doi: 10.1200/JC0.2019.37.7_suppl.TPS538.

21. Kang H, Ho AL, Muzaffar J, Bowles DW, Kim S-B, Ahn M-J, et al. A phase II open-label, multicenter, study to evaluate the efficacy and safety of rivoceranib in subjects with recurrent or metastatic adenoid cystic carcinoma. Journal of Clinical Oncology. 2020;38(15_suppl):TPS6597-TPS. doi: 10.1200/JC0.2020.38.15_suppl.TPS6597.

22. Chawla SP, Chua VS, Gordon EM, Moradkhani A, Kim K, Quon D, et al. Phase I study to evaluate the safety and efficacy of rivoceranib (apatinib) and nivolumab in patients with unresectable or metastatic cancer. Journal of Clinical Oncology. 2019;37(8_suppl):18-. doi: 10.1200/JC0.2019.37.8_suppl.18. 
Figures

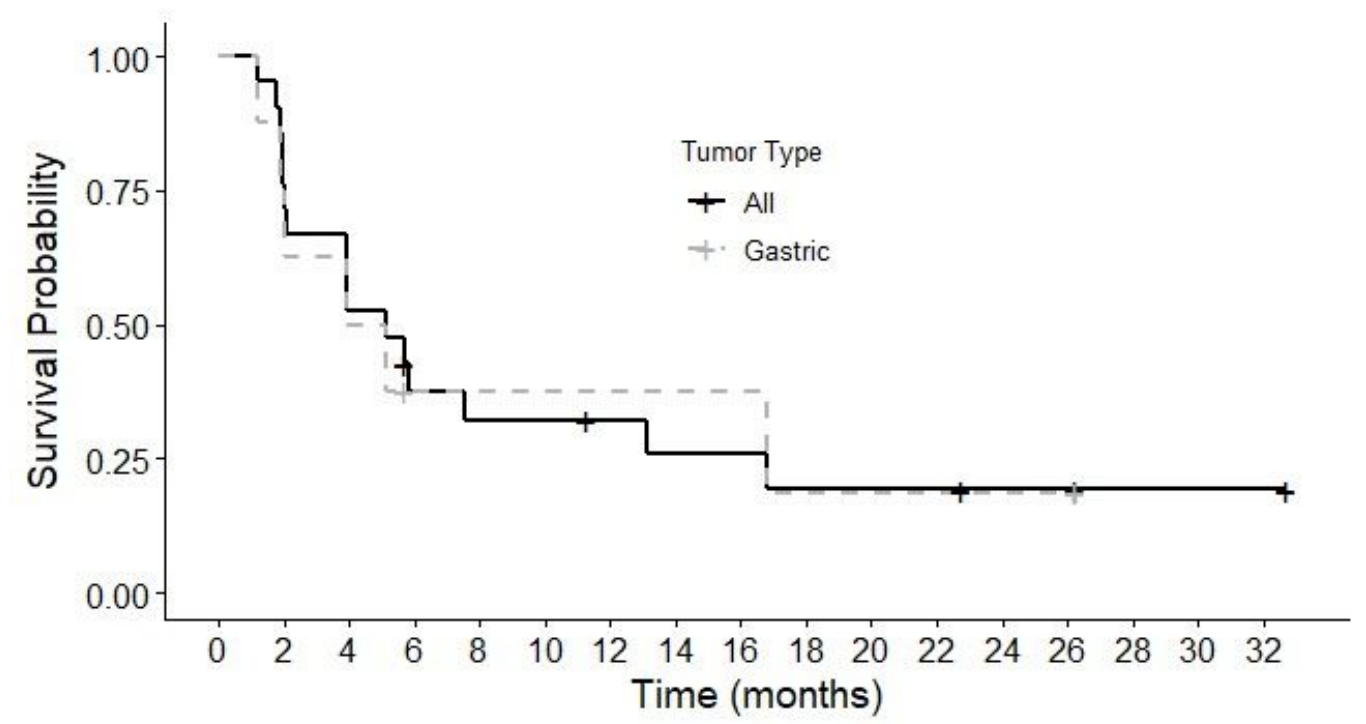

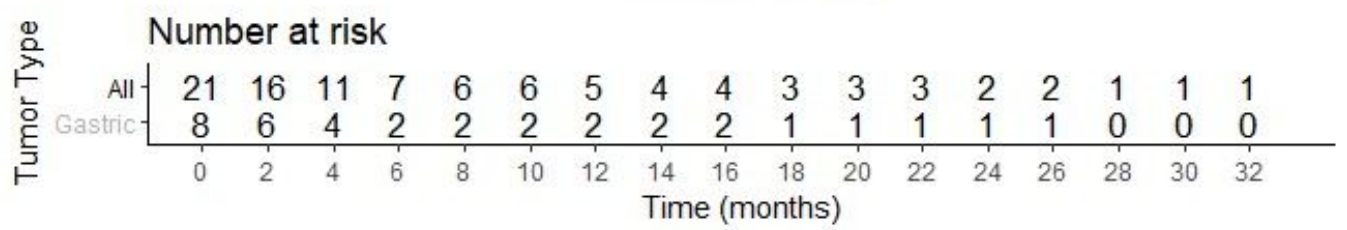

\section{Figure 1}

Progression-free survival of all patients and the gastric cancer patient subset. Median progression-free survival of all patients was 5.1 months (95\% Cl: $2.0-13.1)$ and in gastric cancer patients was 4.5 months (95\% Cl: $1.2-16.8)$. 